\title{
Visual Recovery After Blindness From Pituitary Apoplexy
}

\author{
Andrew D. Parent
}

\begin{abstract}
In a series of 11 patients with classic pituitary apoplexy, two patients had the acute onset of bilateral blindness. After transsphenoidal decompressive surgery both patients had useful recovery of vision. Although impairment of neurologic function appears irreversible when central nervous tissue has been compressed to the point of total loss of function it would appear that the optic chiasm may be an exception to this experience. Our review of the literature and our experience suggests that decompression can be worthwhile even late in the course of this disease and visual loss should not be treated expectantly.
\end{abstract}

RÉSUMÉ: Récupération visuelle après une cécité due à une apoplexie pituitaire Dans une série de 11 patients avec apoplexie pituitaire classique, deux patients ont présenté une cécité bilatérale d'apparition aiguë. Après chirurgie transsphénoïdale décompressive, les deux patients ont récupéré une vision utile. Bien que l'altération d'une fonction neurologique apparaisse irréversible lors que le tissu nerveux central a subi une compression jusqu'à perte fonctionnelle totale, il semblerait que le chiasma optique puisse faire exception à cette constatation. Notre revue de la littérature et notre expérience suggèrent que la décompression peut être utile même à un stade tardif de l'évolution et que la perte visuelle ne doit pas être traitée par l'expectative.

Can. J. Neurol. Sci. 1990; 17:88-91

Acute loss of visual fields and acuity have been considered a prime indication for operative decompression in pituitary apoplexy. Numerous reports have documented recovery in patients who had residual vision. 1,2,3 Patients who are blind or near blind, on the other hand, have a much less optimistic prognosis. There are few reports of recovery after 24 hours of blindness. We present two cases of acute clinical blindness from pituitary apoplexy with return of vision after transsphenoidal surgery.

\section{Patient I}

A 42-year-old black female had been evaluated by an ophthalmologist for a three month history of headaches and diminished vision in her left eye. Her vision had gradually deteriorated to bilateral large irregular central scotomas, greater in the left than the right eye. On July 9th, she presented to the University of Mississippi Medical Center with a one day history of the acute onset of sudden blindness associated with an intense excruciating headache. Neurologic examination demonstrated the pupils to be equal, approximately $4 \mathrm{~mm}$, unreactive to light and in the primary position of gaze. She could not discern light or hand movements. The remainder of her neurologic exam was normal. A CT scan demonstrated a large sella/suprasellar tumor that was approximately $3.5 \mathrm{~cm}$ in size (Figure 1). Despite the blindness of over 36 hours, it was elected to transsphenoidally decompress her chiasm. The surgical pathology report was consistent with pituitary apoplexy with infarction of her large pituitary-null cell tumor. On the second day postoperatively, the patient was able to recognize colors in her left eye, count fingers, and even read large print. Her visual field revealed a preserved inferior nasal field in the left eye (Figure 2). She had no return of vision in her right eye. Her postoperative endocrine status is that of panhypopituitarism, requiring replacement cortisol, thyroid, and DDAVP.

\section{Patient 2}

This 59-year-old white male was referred to the Jackson VA Medical Center with a four day history of an extremely severe headache. This headache was associated with nausea and some vomiting. There was a history of an 80-pound weight gain in the past year, hypertension, decreased libido, as well as a history of an emotional disturbance characterized by neglect, inappropriateness, and poor memory. On examination this was an obese white male with symmetrical gynecomastia. Visual fields by confrontation exam appeared to be normal. His neurologic exam revealed a right 6 th nerve palsy. A CT was obtained which demonstrated a very large enhancing mass in the sella/suprasellar area that measured approximately $6.5 \mathrm{~cm}$ in diameter (Figure 3 ). On the evening of admission, the patient became progressively disoriented and confused. Ophthalmologic evaluation 24 hours after admission demonstrated that the patient had a searching eye gaze and no reflex to threat or bright light. He made no attempt to fix or follow.

On January 15, 1987 the patient had a transsphenoidal resection of a very large pituitary tumor which was noted to be a hemorrhagic mass extending into the sphenoid sinus with exten- 


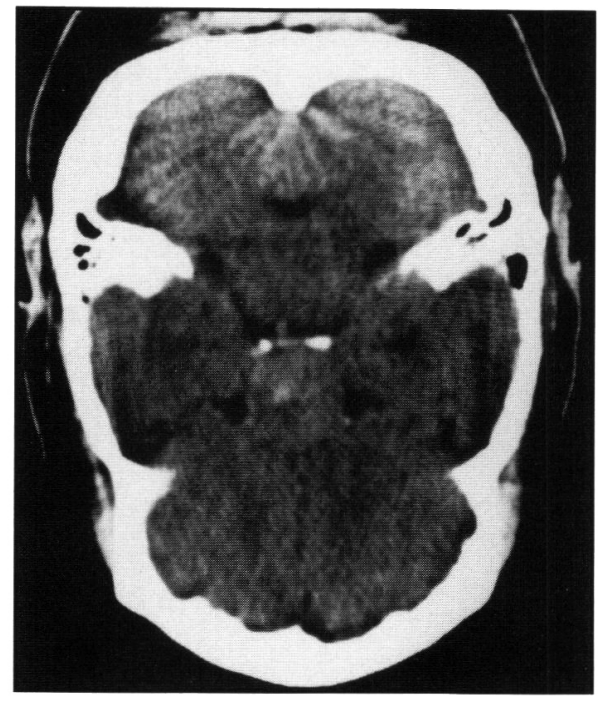

Figure I - CT scan from Patient I showing large sella/suprasellar tumor. sive areas of necrotic tissue. The pathologic report was that of a prolactin cell pituitary adenoma. Postoperatively the patient did not develop diabetes insipidus. Within five days of surgery, the patient's vision had improved to the point of $20 / 30$ bilaterally with persistence of the right sixth nerve palsy. Goldman's visual fields were interpreted as essentially within normal limits at six weeks postoperative. His preoperative prolactin level returned at $1114 \mathrm{ng} / \mathrm{ml}$. He was treated with Bromocriptine $2.5 \mathrm{mg}$ t.i.d. as well as replacement cortisone and synthroid.

\section{Discussion}

Henderson 4 reviewed Cushing's 338 pituitary tumors, and noted seven examples of bilateral blindness. Two patients had slight postoperative return of vision. The possible restoration of sight to a blind eye was also shown in those patients who had only one eye affected. Recovery of vision in an eye that had been blind up to three months was noted in several patients and almost complete recovery was observed in one patient who had been blind for only a few weeks. In other patients, however, who had been blind for greater periods of time, there was no postoperative return of vision. The favorable prognostic influence of the presence of light perception prior to surgery was noted in cases of favorable return of vision. Henderson concluded that visual recovery "cannot be expected in an eye that is

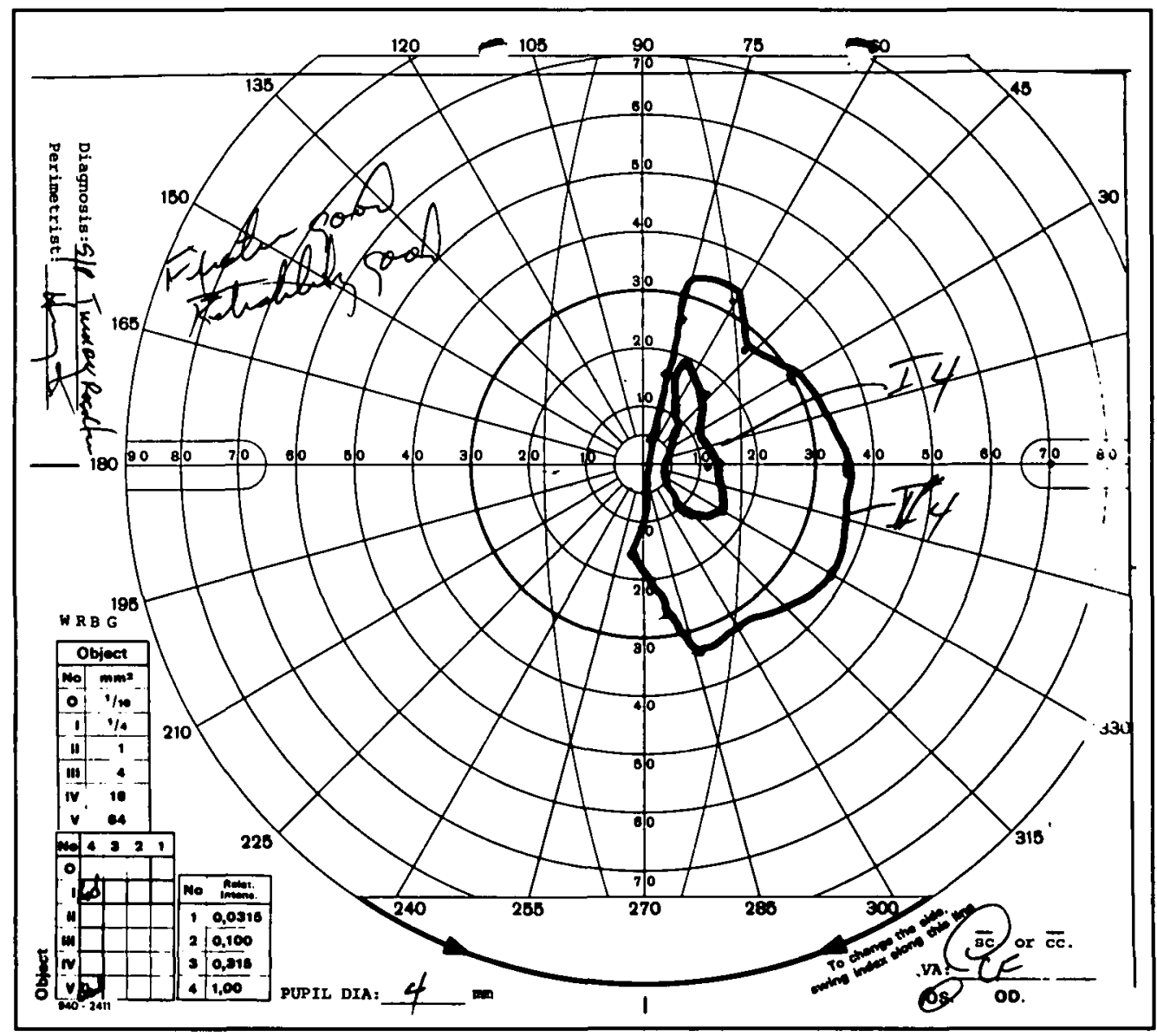

Figure 2 - Visual field for left eye from Patient 1. 


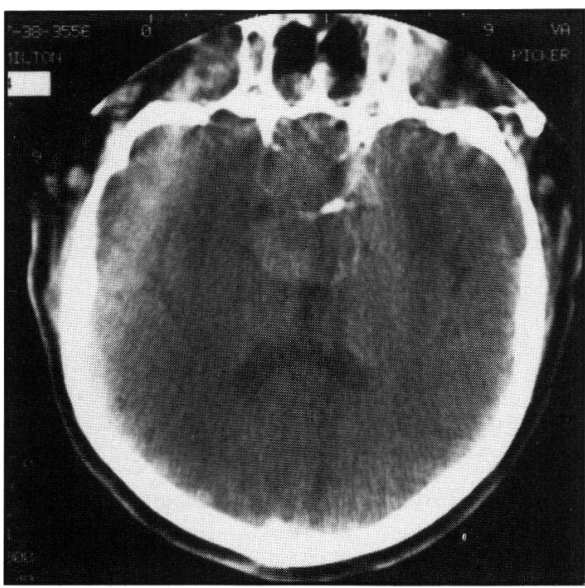

Figure $3-C T$ scan from Patient 2 showing large enhancing mass in the sellalsuprasellar area.

known to have been completely blind for six months or longer".

More recently in the extensive review of 62 patients by Laws et al, 5 only one patient had completely lost his vision and no recovery was documented. Cohen et al, 6 in reviewing 100 consecutive patients with pituitary adenomas with respect to visual recovery, demonstrated no improvement in the four patients who had no light perception preoperatively. In 1982, McLarty et al ${ }^{7}$ presented 11 patients with large pituitary tumors and severe visual deficits, six of whom were blind. One blind patient, case number 5, a 35-year-old female, had a large cystic craniopharyngioma removed and had useful visual recovery postoperatively.

Sudden blindness due to pituitary tumors, as noted by Robinson and $\mathrm{Chir}^{8}$ in 1972, is almost diagnostic of pituitary apoplexy and it is usually associated with headaches, diplopia, and obtundation. Robinson and Chir reported one patient whose left eye progressed to light perception with no evidence of vision in the right eye. Postoperatively this patient's visual fields improved to bilateral hemianopsia.

Shenkin ${ }^{9}$ in 1955 reported one case of complete blindness after pituitary apoplexy with recovery of a left temporal visual field but with persistent right eye blindness.

Mohr and Hardy 10 had two cases of unilateral blindness in four patients with pituitary apoplexy. One patient totally regained his vision. They noted that hemorrhagic changes were found in $9.6 \%$ of their cases, but the classic syndrome of pituitary apoplexy was less commonly noted. Although theoretically, apoplexy could be due to either hemorrhage or infarction, most reported cases of sudden visual blindness are associated with hemorrhage into a pituitary macroadenoma.

A major problem in evaluating clinical return of vision in patients rendered blind by pituitary apoplexy is that often preoperative formal ophthalmologic evaluations have not been performed, especially since the patients are often lethargic, uncooperative or obtunded. Furthermore, the number of cases are few and often anecdotally reported (Table 1). In our review of the literature, we found 19 cases of bilateral blindness and 46 cases
Table 1: Published Results of Recovery from Preoperative Blindness

\begin{tabular}{llcl}
\hline \hline & \# of Cases & Improved & Duration \\
\hline Henderson & 7 Bilateral & 2 & not reported \\
(Cushing) (1939) & 28 Unilateral & 8 & 1 year \\
Shenkin (1955) & 1 Unilateral OD & 1 & 12 days \\
Robinson (1972) & 1 Bilateral & 1 & 5 days \\
& 1 Unilateral OD & 1 & 10 days \\
Rovit (1972) & 1 Unilateral OS & 1 & $21 / 2$ days \\
1 Unilateral OS & 1 & 3 days \\
Goodman (1973) & 1 Bilateral & 1 & 5 days \\
Laws (1977) & 1 Unilateral OS & 1 & 3 days \\
McLarty (1982) & 6 Bilateral & 0 & not reported \\
& 3 Unilateral & 1 & not reported \\
Mohr (1982) & 2 Unilateral OD & 0 & not reported \\
Symon (1982) & 2 Bilateral & 2 & days \\
Waybright (1983) & 4 Unilateral & 0 & not reported \\
Striph (1984) & 1 Unilateral & 1 & OD 23 days \\
Cohen (1985) & 4 Unilateral & 0 & not reported \\
Parent (1987) & 2 Bilateral & 2 & 11/2 days \\
\hline
\end{tabular}

of unilateral blindness due to pituitary tumors with documentation of some visual recovery in nine of the bilateral cases and 15 of the unilateral cases. The longest duration of time between onset of bilateral blindness and visual recovery was five days. 8,11 Visual recovery from unilateral blindness has been recorded after one year. ${ }^{4}$

In the past seven years we have seen 11 patients with pituitary apoplexy. Only two patients presented with normal visual fields. Four patients did not have cranial nerve deficits but the remaining patients had either a third and/or sixth cranial nerve involvement. Two patients had unilateral blindness of an eye that improved in one case. Six patients had bitemporal hemianopic field defects. The patients ranged from $25-76$ years of age. In no case did the patients' visual fields worsen postoperatively. Eight patients required replacement cortisone and synthroid, but only four of 11 patients developed diabetes insipidus.

Although chiasmal compression from a pituitary tumor usually affects predominantly the peripheral visual fields, acute compression apparently compromises both peripheral and central vision. Findlay et al ${ }^{12}$ noted that visual recovery is favorably related to younger patients as well as a shorter period of visual deficits and small tumor size. The clinical finding of a relatively normal optic nerve on ophthalmologic examination may be considered a good prognostic sign. Visual evoked responses have not correlated with the observed damage to an optic nerve. ${ }^{13}$ Specifically, the absence of wave forms from stimulating a blind eye does not necessarily portend a poor prognosis.

The pressure induced changes in the optic nerve structure and function have been studied clinically as well as histopathologically. Neuroconduction deficits may be due to ischemia secondary to vascular compression, interruption of axoplasmic flow, or direct damage to the neuro-supporting tissues of the optic nerve. Experimentally myelin is known to be reversibly damaged by compression with functional return after remyelina- 
tion. Clifford-Jones et al ${ }^{14}$ showed by an inflatable balloon model that this occurred in the cat's optic nerve. Presumably, patients without return of vision may have had vascular compromise of the optic nerve, rather than compressive demyelination.

Our experience suggests that decompression can be worthwhile even late in the course of this disease and, therefore, visual loss should not be treated expectantly. In our opinion, transsphenoidal surgery is the optimal approach to decompress the optic pathways in cases of pituitary apoplexy.

\section{REFERENCES}

1. Krueger EG, Unger SM, Roswit B. Hemorrhage into pituitary adenoma with spontaneous recovery and reossification of the sella turcica. Neurology (Minneap) 1960; 10: 691-696.

2. Markowitz S, Sherman L, Kolodny HD, et al. Acute pituitary vascular accident (pituitary apoplexy). Med Clin North Am 1981; 65(1): $105-116$

3. Trautmann JC, Laws ER Jr. Visual status after transsphenoidal surgery at the Mayo Clinic, 1971-1982. Am J Ophthalmol 1983; 96: 200-208.

4. Henderson WR. The pituitary adenomata - a follow-up study of the surgical results in 338 cases (Dr. Harvey Cushing's series). Br J Surg 1939; 26: 811-921.

5. Laws ER Jr, Trautman JC, Hollenhorst RW. Transsphenoidal decompression of the optic nerve and chiasm - visual results in 62 patients. J Neurosurg 1977; 46: 717-722.

6. Cohen AR, Cooper PR, Kupersmith MJ, et al. Visual recovery after transsphenoidal removal of pituitary adenomas. Neurosurgery 1985; 17(3): 446-452.
7. McLarty DG, Kermali W, Makene WJ. Pituitary tumours and blindness: continuation of the Pre-Harvey Cushing era in developing countries. Lancet 1982; 2: 810-811.

8. Robinson JL, Chir B. Sudden blindness with pituitary tumors: report of 2 cases. J Neurosurg 1972; 36: 83-85.

9. Shenkin H. Relief of amblyopia in pituitary apoplexy by prompt surgical intervention. JAMA 1955; 159: 1622-1624.

10. Mohr G, Hardy J. Hemorrhage, necrosis, and apoplexy in pituitary adenomas. Surg Neurol 1982; 18(3): 181-189.

11. Rovit RL, Fein JM. Pituitary apoplexy: a review and reappraisal. J Neurosurg 1972; 37: 280-288.

12. Findlay F, McFadzean RM, Teasdale G. Recovery of vision following treatment of pituitary tumours; application of a new system of assessment to patients treated by transsphenoidal operation. Acta Neurochir (Wien) 1983; 68: 175-186.

13. Striph GG, Slamovits TL, Burde RM. Visual recovery following prolonged amaurosis due to compressive optic neuropathy. J Clin Neuro-ophthalmol 1984; 4: 189-195.

14. Clifford-Jones RE, Landon DN, McDonald WI. Remyelination during optic nerve compression. J Neurol Sci 1980; 46: 239-243.

15. Symon L, Mohanty S. Hemorrhage in pituitary tumours. Acta Neurochir 1982; 65: 41, 49.

16. Waybright EZ, Selhorst JB, Young HF, et al. Tumors compressing the optic nerve: diagnosis and surgical results. VA Med 1983; 110: 230-234.

17. Goodman JM, Gilson M, Shapiro B. Pituitary apoplexy - a cause of sudden blindness. J Indiana State Med Assoc 1973; 66: 320 321. 